\title{
An outbreak of toxoplasmosis in an aviary collection of Nicobar pigeons (Caloenas nicobaria)
}

\author{
R D Last ${ }^{\mathrm{a}^{*}}$ and $\mathrm{H}$ L Shivaprasad ${ }^{\mathrm{b}}$
}

\begin{abstract}
Three out of 10 Nicobar pigeons (Caloenas nicobaria) in an aviary collection in South Africa were found dead with no presenting clinical symptoms. Histological examination of formalin-fixed tissues from all these birds revealed necrotic foci in various visceral organs (liver, spleen, heart, kidney and lungs), plus diffuse pulmonary congestion and oedema with vasculitis. Numerous protozoal tachyzoites were present in all organs and there was strong positive immunohistochemical (IHC) labelling of these organisms for Toxoplasma gondii. Pathology was consistent with acute systemic toxoplasmosis as a consequence of oocyst ingestion. Feral cats were known to be a problem at the facility. Clinical toxoplasmosis is rarely reported in pigeons and this is believed to be the 1st report of toxoplasmosis in Nicobar pigeons.
\end{abstract}

Key words: aviary, Caloenas nicobaria, Nicobar pigeons, toxoplasmosis.

Last R D, Shivaprasad H L An outbreak of toxoplasmosis in an aviary collection of Nicobar pigeons (Caloenas nicobaria). Journal of the South African Veterinary Association (2008) 79(3): 149-152 (En.). Vetdiagnostix - Veterinary Pathology Services, P.O. Box 13624, Cascades, 3202, South Africa.

\section{INTRODUCTION}

Toxoplasmosis is an uncommon, but frequently fatal parasitic disease of mammals, birds and reptiles, caused by the protozoan Toxoplasma gondii ${ }^{1,8,17}$. The life cycle of this parasite is indirect, with Felidae being the definitive hosts and a broad range of non-feline hosts (mammals, avians and reptiles), as well as cats, serving as intermediate hosts ${ }^{15,7,8,20,22}$. The typical coccidian enteroepithelial cycle, with both schizogonic and gametogenic development phases in the intestinal epithelium and the shedding of oocysts in the faeces, only occurs in the definitive feline hosts ${ }^{1,8,30}$. The extraintestinal (tissue) cycle, with intestinal invasion and visceral dissemination by tachyzoites and progression to bradyzoite-filled tissue cysts, represents the entire life cycle of T. gondii in avians and other intermediate hosts $^{1,5,8,20}$. The proliferating tachyzoite stages of the parasite induce the pathological changes, dominated by multifocal areas of necrosis in various organ systems ${ }^{1,10,12,13}$. In birds that survive long enough to develop adequate specific cell-mediated immunity, tachyzoite replication is arrested and bradyzoite-filled

avetdiagnostix - Veterinary Pathology Services, P.O. Box 13624, Cascades, 3202, South Africa.

${ }^{\mathrm{b}}$ California Animal Health and Food Safety Laboratory

Avenue, Fresno, CA 93725, USA.

${ }^{*}$ Author for correspondence.

E-mail: vetdiagnostix@ futurenet.co.za

Received: June 2008. Accepted: August 2008. tissue cysts are formed, which are clinically quiescent $t^{1,10,12,13,24}$. Tissue cysts usually persist for life, but in instances where there is immune suppression, reactivation of cysts may occur, with release of tachyzoites and renewed proliferation $^{8,13}$. Such recrudescent toxoplasmosis is not well documented in avian species $^{1,8,10,12,13}$.

Modes of transmission of T. gondii to avians are via the ingestion of faeces contaminated by sporulated oocysts from Felidae, ingestion of transport hosts (coprophagous arthropods, earthworms) or the carnivorous ingestion of tachyzoites and bradyzoite cysts in animal tissues $^{1,21,28,31}$.

Natural infections have been reported in a wide range of wild birds, chickens, turkeys and ducks ${ }^{1,12,15}$. Most infections are inapparent with no overt clinical disease $\mathrm{e}^{1,3,10,12,19}$. However, under certain ecological conditions outbreaks of acute systemic disease have been reported $^{1,9,27,30,32,33}$. There appears to be variation amongst avian species in susceptibility to disease, with some species being fairly resistant to infection while other species seem to be highly susceptible $1,2,6,24,27,30,33$. Little has been published on clinical toxoplasmosis in pigeons, and this is believed to be the 1st report of toxoplasmosis in Nicobar pigeons (Caloenas nicobaria). The natural habitat of this rare ground pigeon is restricted to the Nicobar and Andaman islands of Asia ${ }^{16}$.

\section{CASE HISTORY}

A bird park in Durban, KwaZulu-Natal, South Africa, had a collection of mixed age and sex Nicobar pigeons that were housed in a single display flight. In April 2003, 25 birds were removed from this flight and divided into 10 breeding pairs, 4 spare cocks and 1 hen. Five pairs were sent to another of the company's bird parks in Johannesburg, Gauteng, South Africa, while the other 5 breeding pairs were rehoused at the Durban facility. The 4 spare cocks and hen remained in the original display flight.

In Durban this brand new flight had a river sand base with new perches and nesting boxes. The 5 breeding pairs were placed in this flight on 10 April 2003. The 1st mortality occurred in January 2004, the bird being found dead with no clinical signs. After a 2nd death a few days later the birds were moved to another flight with a solid concrete base. One other death occurred a week later. The remaining birds were subsequently rehoused in another flight with river sand base and no problems have been reported. No nicobars died in the Johannesburg facility. Feral cats were reported as being a problem at the Durban facility.

Necropsies on the 3 nicobars that died were performed by bird park personnel and only formalin-fixed tissues were forwarded to the laboratory for histological examination. Organs received in 10\% buffered formalin from these 3 birds included lung, liver, kidney, heart, spleen, proventriculus, small intestine and pancreas. Histological sections were prepared by routine histological procedures, stained with Meyers haematoxylin and eosin (H\&E) and examined microscopically.

Microscopic examination revealed severe diffuse pulmonary congestion with interstitial oedema and fibrinoid vasculitis (Fig. 1). Randomly scattered through the section were foci of necrosis with heterophil infiltration. In macrophages and unidentified cells in the interstitial compartment of airway capillaries and endothelial cells of blood vessels, large numbers of protozoal organisms were observed (Figs 1, 2). The organisms measured 5-7 

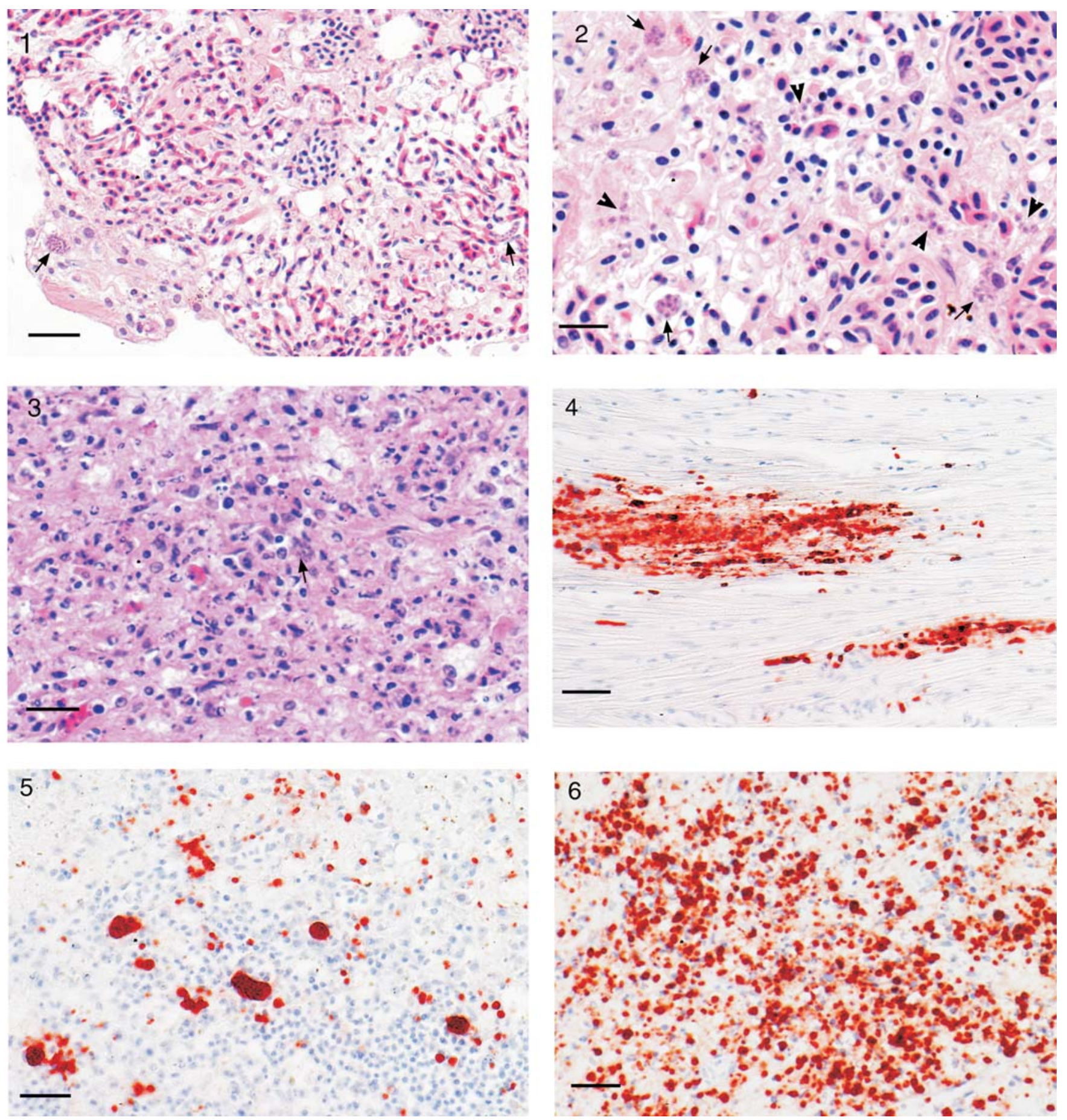

Figs 1-6. 1: Lung with oedema and a few tissue cysts of Toxoplasma gondii (arrows), haematoxylin and eosin. 2: Lung with oedema, inflammation and numerous tissue cysts (arrows) and free tachyzoites (arrowheads) of Toxoplasma gondii, haematoxylin and eosin. 3: Kidney with severe necrosis, fibrin and inflammation and a tissue cyst of Toxoplasma gondii (arrow), haematoxylin and eosin. 4: Heart showing many free tachyzoites of Toxoplasma gondii in the myocardium, streptavidin-biotin immunoperoxidase method. 5: Spleen showing numerous cysts and tachyzoites of Toxoplasma gondii, streptavidin-biotin immunoperoxidase method. 6: Kidney showing numerous tachyzoites of Toxoplasma gondii, streptavidin-biotin immunoperoxidase method. Scale bars: $1=120 \mu \mathrm{m} ; 2,3,6=50 \mu \mathrm{m} ; 4,5=75 \mu \mathrm{m}$.

microns in diameter, were spherical to tear-drop shaped with round to oval basophilic bodies (nucleus) measuring 3-4 microns in diameter (Fig. 2). A clear halo between the nucleus and cell membrane of the protozoa was noted. In some places tissue cysts containing numerous protozoa were observed (Figs 1,2). Hepatic pathology included dense portal infiltrates of mixed mononuclear cells and heterophils with cholangitis and protozoal organisms. Apoptosis and necrosis of predominantly periportal hepatocytes with similar protozoal organisms were observed. Splenic sections revealed multifocal areas of necrosis with numerous protozoal organisms. Interstitial myocarditis with visible protozoal organisms characterized the myocardial pathology. In the kidney there was interstitial inflammation with vasculitis and locally extensive ulceration of one of the collecting tubules and inflammation associated with similar protozoal organisms (Fig. 3).
Sections of lungs, heart, liver, spleen and kidney were tested immunohistochemically (IHC) using rabbit polyclonal T. gondii antibodies (Dako, Carpinteria, California) according to the manufacturer's instructions. To avoid the endogenous peroxidases and biotin in avian tissues, a Dako En Vision Horseradish - Peroxidase (HRP) rabbit kit was used. For the chromogen 3-amino, 9-ethyl-carbazole (AEC) from Vector Labs (Burlingame, CA) was used. Briefly, the procedure included 
dewaxing of sections, quenching with $3 \%$ hydrogen peroxide, digestion in $0.4 \%$ pepsin, rinsing in $0.5 \%$ casein, treatment with primary antibody at 1:1200 dilution, treatment with HRP solution for $30 \mathrm{~min}$ utes and treatment with AEC. Sections were then counterstained with haematoxylin, air-dried, provided with a cover slip and examined microscopically.

Tachyzoites appeared larger and more numerous in IHC-labelled sections than on H\&E sections. Organisms, both individually and in cysts, were seen most commonly in the lungs, heart (Fig. 4) and spleen (Fig. 5), while in the kidney (Fig. 6) numerous individual organisms predominated.

A small piece of lung tissue from the paraffin wax block was selected, dewaxed in xylene and alcohol, post-fixed in $2.5 \%$ Glutaraldehyde followed by osmium tetroxide. It was then embedded and sectioned according to Buzzola and Russel, $1991^{4}$. Ultrastructuarally the organisms in the lung had the typical appearance of Apicomplexa, with a nucleus situated almost in the middle with a conoid, many micronemes and rhoptries.

\section{DISCUSSION}

Although infection of wild and domestic avian species is considered common, development of clinical disease is considered $\operatorname{rare}^{1,12,17,25}$. In susceptible avian species acute systemic toxoplasmosis is characterised by necrotic foci in various visceral organs (liver, spleen, heart, lungs, skeletal muscle, central nervous system), plus diffuse pulmonary congestion and oedema with vasculitis ${ }^{1,9,10,12,15,17}$. Recrudescent infections, on the other hand, tend to have lesions restricted to or most prominent in the central nervous system, skeletal muscle and myocardium, as these are the main locations for the bradyzoitecontaining lesions ${ }^{1,12,13,29}$. In the birds described here the wide visceral distribution and severity of lesions, as well as the heavy parasite load of tachyzoite stages demonstrated by immunohistochemistry, would be considered more consistent with acute systemic disease than recrudescent infection.

There appears to be variation among avian species with regard to susceptibility to T. gondii infection ${ }^{2,6,10,12,24,27,33}$. Chickens and raptors appear to be fairly resistant to acute systemic disease, and in the case of poultry, also experimental infection, with rapid development of quiescent tissue cysts $^{1,2,12,24}$. Canaries, geese and some corvid species have been reported to be highly susceptible to acute systemic toxoplasmosis. Clinical toxoplasmosis is deemed to be a significant threat to the survival of the highly endangered Alala
(Corvus hawaiiensis) in its natural habitat on the islands of Hawaii ${ }^{2,3,23,32,33}$. Lesions described for toxoplasmosis also show some degree of variation among species. Canaries and possibly other passerines commonly present with ocular lesions (non-suppurative chorioretinitis), raptors have most commonly been infected with encysted stages of the parasite and disseminated disease has frequently been described in quail, mynahs and canaries. Acute pneumonic lesions with severe congestion and oedema have been described in parrots, geese and pigeons , $7,9,17,23,24,30,32^{\text {. }}$.

Clinical toxoplasmosis is rarely reported in pigeons, although the disease has been described in experimentally as well as naturally infected birds. Fatal disease has been documented in Torres Strait pigeons (Ducula spilorrhoa), Wonga pigeons (Leucosarcia melanoleuca), Scheepmaker's crowned pigeons (Goura scheepmakeri sclaterii) and domestic pigeons (Columbia livia domestica $)^{2,7,17,21,26}$. The cases described here are believed to be the 1st report of toxoplasmosis in Nicobar pigeons. The use of toxoplasma serology in the diagnosis of toxoplasmosis in this species remains somewhat controversial. Pigeons usually develop high antibody titres following infection, although one study demonstrated seroconversion without high titres, but there appears to be little correlation with clinical disease and seroprevalance of $T$. gondii is reported to be ${ } \mathrm{w}^{2,21,26}$. In addition, low serum dilutions and potential cross-reactions with other infectious agents can complicate interpretation of results ${ }^{14}$.

The diagnosis of toxoplasmosis in these birds was based on histological lesions, the structure of intralesional protozoal organisms, specific immunoreactivity to T. gondii antisera with IHC labelling and electron microscopic features of these protozoa. The source of infection in this outbreak was believed to be feral cats, which were reported to be a problem at this particular facility.

\section{ACKNOWLEDGEMENTS}

The authors are grateful to $\mathrm{Mr}$ Bob Nordhausen for preparation and production of the EM samples and Dr Rocio Crespo and Ms Rebecca Gonzales for assistance with the photography, both of whom are from the California Animal Health and Food Safety Laboratory System, Fresno Branch, University of California, Davis.

\section{REFERENCES}

1. Bermudez A J 2003 Miscellaneous and sporadic protozoal infections. In Saif Y M (ed.) Diseases of poultry (11th edn). Iowa State Press, Ames: 1018-1020

2. Biancifiori F, Rondini C, Grelloni V, Frescura
T 1986 Avian toxoplasmosis: experimental infection of chicken and pigeon. Comparative Immunology, Microbiology and Infectious Diseases 9: 337-346

3. Bickford A A, Sanders D 1996 Experimental toxoplasmosis in chickens. American Journal of Veterinary Research 27: 308-318

4. Buzzola J J, Russel L D 1991 Electron microscopy, principles and techniques for biologists. Jones and Bartlett, New York

5. Center S A 1996 Acute hepatic injury: hepatic necrosis and fulminant hepatic failure. In Gulford W G, Center S A, Strombeck D R (eds) Small animal gastroenterology (3rd edn). W B Saunders, Philadelphia: 683

6. Dhillon A S, Thacker H L, Winterfield R W 1981 Toxoplasmosis in mynahs. Avian Diseases 26:445-449

7. Dorestein G M, Mensink M M H C 2002. Avian pathology challenge. Journal of Avian Medicine and Surgery 16: 240-244

8. Dubey J P 1994 Toxoplasmosis. Journal of the American Veterinary Medical Association 205: 1593-1598

9. Dubey J P, Garner M W, Willette M M, Batey K L, Gardiner, C H 2001 Disseminated toxoplasmosis in magpie geese (Anseranas semipalmata) with large numbers of tissue cysts in livers. Journal of Parasitology 87: 219-223

10. Dubey J P, Goodwin M A, Ruff M D, Shen S K, Kwok O C H, Wizlkins G L, Thulliez P 1995 Experimental toxoplasmosis in chukar partridges (Alectoris graeca). Avian Pathology 24: 95-107

11. Dubey J P, Porter S L, Tsebgm F M, Shen S K, Thulliez, P 1992 Induced toxoplasmosis in owls. Journal of Zoo and Wildlife Medicine 23: 98-102

12. Dubey J P, Webb D, Sundar N, Velmurugan G, Bandini L, Kwok O, Su C 2007 Endemic avian toxoplasmosis on a farm in Illinois: clinical disease, diagnosis, biologic and genetic characteristics of Toxoplasma gondii isolates from chickens (Gallus domesticus) and a goose (Anser anser). Veterinary Parasitology 148: 207-212

13. Frenkel J K1973 Toxoplasmosis: parasite life cycle, pathology and immunology. In Hammond D M, Long P L (eds) The Coccidia, Eimeria, Isospora, Toxoplasma and related genera. University Park Press, Baltimore: 342-410

14. Frenkel J K 1981 False-negative serological tests for Toxoplasma in birds. Journal of Parasitology 67: 952-953

15. Greiner E C, Ritchie B W 1994 Parasites. In Ritchie B W, Harrison G J, Harrison L R (eds) Avian medicine: principles and application. Winger's Publishing, Florida: 1017

16. Grimmett R., Inskipp C, Inskipp T 1998 Birds of the Indian subcontinent. Oxford University Press, Delhi

17. Hartley W J, Dubey J P 1991 Fatal toxoplasmosis in some native Australian birds. Journal of Veterinary Diagnostic Investigation 3: 167-169

18. Howerth E W, Rich G, Dubey J P, Yogasundram K 1991 Fatal toxoplasmosis in a red lory (Eos bornea). Avian Diseases 35: 642646

19. Jacobs L, Melton M L 1996 Toxoplasmosis in chickens. Journal of Parasitology 52: 11581162

20. Jones T J, Hunt R D, King N W 1996 Veterinary pathology (6th edn). Williams \& Wilkins, Baltimore: 555-561

21. Kirkpatrick C E, Colvin B A, Dubey J P 1990. Toxoplasma gondii antibodies in common barn owls (Tyto alba) and pigeons (Columbia 
livia) in New Jersey. Veterinary Parasitology 36: 177-180

22. Lappin M R 2000 Protozoal and miscellaneous infections. In Ettinger $S \mathrm{~J}$, Feldman E C (eds) Textbook of veterinary internal medicine (5th edn). W B Saunders, Philadelphia: $410-413$

23. Lindsay D S, Gasser R B, Harrigan K E, Madill D N, Blagburn B L 1995 Central nervous system toxoplasmosis in roller canaries. Avian Diseases 39: 204-207

24. Lindsay D S, Smith P C, Hoerr F J, Blagburn B L 1993 Prevalence of encysted Toxoplasma gondii in raptors from Alabama. Journal of Parasitology 79: 870-873

25. Mason R W, Hartley W J, Dubey J P 1991 Lethal toxoplasmosis in a little penguin (Eudyptula minor) from Tasmania. Journal of Parasitology 77: 328
26. Mushi E Z, Binta M G, Chabo R G, Ndebele R, Panzirah R 2001 Seroprevalence of Toxoplasma gondii and Chlamydia psittaci in domestic pigeons (Columbia liva domestica) at Sebele, Gaborone, Botswana. Onderstepoort Journal of Veterinary Research 68: 159161

27. Parenti E, Cerruti Sola S, Turilli C, Corazzola S 1986 Spontaneous toxoplasmosis in canaries (Serinus canaria) and other small passerine cage birds. Avian Pathology 15: 183-197

28. Ruiz A, Frenkel J K 1980. Intermediate and transport hosts of Toxoplasma gondii in Costa Rica. American Journal of Tropical Medical Hygiene 29: 1161-1166

29. Summers B A, Cummings J F, de Lahunta A 1995. Veterinary neuropathology. Mosby, St Louis, MO: 163-169
30. Vickers M C, Hartley W J, Mason R W, Dubey J P, Schollam L 1992. Blindness associated with toxoplasmosis in canaries. Journal of the American Veterinary Medical Association 200: 1723-1725

31. Wallace G D 1973 Intermediate and transport hosts in the natural history of Toxoplasma gondii. American Journal of Tropical Medical Hygiene 22:456-464

32. Williams S M, Fulton R M, Render J A Mansfield L, Bouldin M 2001 Ocular and encephalic toxoplasmosis in canaries. Avian Diseases 45: 262-267

33. Work T M, Massey J G, Rideout B A, Gardiner C H, Ledig D B, Kwok O C, Dubey J P 2000 Fatal toxoplasmosis in free ranging endangered Alala from Hawaii. Journal of Wildlife Diseases 36: 205-212 